\title{
EGFR Mutation Analysis
}

National Cancer Institute

\section{Source}

National Cancer Institute. EGFR Mutation Analysis. NCI Thesaurus. Code C158872.

A procedure used to detect and identify mutations in the EGFR gene. 